\title{
As novas tecnologias no ambiente escolar. resposta dos professores de Educação Física da Secretaria Municipal de Educação do Rio de Janeiro com relação a Educopédia
}

\author{
New technologies in the school environment: response of teachers \\ of Physical Education of the Municipal Secretariat of Education of \\ Rio de Janeiro in relation to Educopédia
}

1 Glhevysson dos Santos Barros guersonbarros@gmail.com

2 Glaucia Regina da Silva Santos

1 Professor da SME-RJ - UNIGRANRIO.

2 Professora da SME-RJ - UUNIGRANRIO.

\section{Resumo}

0 presente artigo tem como objetivo apresentar uma pesquisa quantitativa que relata os impactos das novas tecnologias no ambiente escolar, em especial a Plataforma Educopédia, e de que forma os professores de Educação Física da Rede Municipal do Rio de Janeiro lidam com essas novas ferramentas. Além disso, ressalta a importância dessas novas possibilidades tecnológicas para a formação continuada desses docentes, além de possibilitar a aprendizagem da utilização das tecnologias, articula a construção de uma metodologia na qual as mídias tecnológicas podem ser recursos didáticos. Para tanto, apresenta-se o questionário aplicado a esses professores e gráficos ilustrativos por meio dos quais se têm acesso ao resultado dessa pesquisa junto aos referidos docentes. Assim, o estudo concluiu que apesar de demandar tempo quanto à montagem dos equipamentos tecnológicos para acessar a Plataforma, isso não é o suficiente para invalidar seu uso nas aulas, pois a Educopédia apresenta conteúdos de qualidade, além de poder trabalhar de forma interdisciplinar e ser indicado para outros profissionais.

Palavras-chave: Tecnologias. Educação física. Docentes.

\begin{abstract}
The present article aims to present a quantitative research that reports the impacts of new technologies in the school environment, especially the Education Platform (Educopédia) and how the Physical Education teachers of the Rio de Janeiro Municipal Network deal with these new tools. In addition, it emphasizes the importance of these new technological possibilities for teachers continued education, which besides making possible the learning of the use of technologies, articulates the construction of a methodology in which technological media can be used as didactic resources. To do so, the questionnaire applied to these teachers and illustrative graphics through which access the result of this research is presented. Thus, the study concluded that although it takes time to assemble the technological equipment to access the Platform, it is not enough to invalidate its use in class, because Educopédia presents quality content, besides being able to work in an interdisciplinary way and be indicated for other professionals.
\end{abstract}

Keywords: Technologies. PE. Teachers.

\section{Como você deve citar?}

BARROS, Glhevysson dos Santos; SANTOS, Glaucia Regina da Silva. As novas tecnologias no ambiente escolar: resposta dos professores de educação física da secretaria municipal de educação do Rio de Janeiro com relação a educopédia. Cadernos UniFOA, Volta Redonda, n. 41, p. 77-83, dezembro 2019. 
As novas tecnologias no ambiente escolar: resposta dos professores de Educação Física da Secretaria Municipal de Educação do Rio de Janeiro com relação a Educopédia

\section{INTRODUÇÃO}

Atualmente, a tecnologia faz parte do cotidiano da sociedade, já que não nos comunicamos mais sem o auxílio dessa ferramenta. O jovem, em particular, não se desvincula dos seus aparatos eletrônicos. É muito comum que um adolescente não atenda a uma ligação feita pelo método tradicional, mas responda a uma mensagem enviada para o mesmo aparelho ao qual está conectado. Logo, a tecnologia, que também vem sendo utilizada amplamente nos meios profissionais, vem modificando a dinâmica cotidiana da sociedade. Castells (1999) declara que vivemos em uma sociedade denominada sociedade em rede, ou seja, não há limites para o alcance da informação.

Muito se avançou, de maneira geral, nas concepções destas tecnologias em nossa sociedade. Até o ano 2000 a sociedade era denominada como era do conhecimento. A partir do ano 2000 , a concepção que tem maior expressão, é a era das conexões (GUERREIRO \& BATTINI, 2014, p. 298).

Dessa forma, a escola não pode ficar fora desse contexto, considerando que ela representa um importante ambiente de socialização de crianças e jovens. É interessante que ocorra uma interação escola/ tecnologia/ aluno, para que o processo ensino-aprendizagem se desenvolva satisfatoriamente, ou seja, tornando o ambiente escolar mais atraente.

Visando a uma modernização e à inserção das práticas educacionais no mundo contemporâneo, a Secretaria Municipal de Educação do Rio de Janeiro (SME-RJ) criou a Educopédia, uma plataforma de aulas digitais on-line de cada disciplina. Essa plataforma conta com material de suporte aos professores, planos de aula, jogos pedagógicos e vídeos ${ }^{3} .0$ objetivo do programa é tornar o ensino mais atraente para os educandos, além de dar suporte aos professores para um melhor desempenho de suas atividades pedagógicas, integrando-as às tecnologias. Além do suporte para desempenho das aulas, a plataforma também oferece cursos de formação continuada para os professores.

De acordo com Alarcão (2001), a formação continuada do professor é uma exigência, pois não termina nesse contexto em que as tecnologias se transformam rapidamente. Cabe ressaltar que a responsabilidade de inovação tecnológica em salas de aula não é somente do professor. Gestores de instituições educacionais também devem estar envolvidos e empenhados para que uma interlocução entre tecnologia e aprendizagem seja uma realidade.

Diante desse contexto, o presente trabalho tem como objetivo desenvolver uma pesquisa quantitativa para mensurar o índice de utilização da Educopédia pelos professores de Educação Física da Rede Municipal do Rio de Janeiro, sua aceitação e o impacto dessa ferramenta na prática docente.

\section{MATERIAL E MÉTODO}

Conduzimos uma pesquisa do tipo quantitativa, cujo instrumento de coleta de dados foi um questionário on-line com 160 docentes de educação física da SME-RJ com média de idade de 25 a 34 anos, de quatro Coordenadorias Regionais de Educação (CRE). O questionário foi enviado apenas para os professores que trabalham no município do Rio de Janeiro, nessas quatro CREs. 0 questionário foi realizado por meio de um programa chamado SurveyMonkey, que é uma ferramenta para pesquisas on-line, sendo encaminhados aos docentes da $3^{\mathrm{a}}, 4^{\mathrm{a}}, 10^{\mathrm{a}}, 11^{\mathrm{a}}$ CRE por meio de um link, através de e-mail ou pelas redes sociais. As demais CREs não participaram do estudo, pois não haveria tempo hábil para a coleta de dados. Ao clicar nesse link, o professor era direcionado ao questionário. É im-

3 http://www.rio.rj.gov.br/web/sme/educopedia 
portante destacar que os participantes da pesquisa, em hipótese alguma, foram identificados, sendo suas participações de forma anônima.

No que se refere aos procedimentos éticos, cabe ressaltar que o projeto de pesquisa foi avaliado pelo Comitê de Ética em Pesquisa (CEP) da Universidade do Grande Rio - UNIGRANRIO, sob o CAAE $n^{\circ}$ 53141215.5.0000.5283, e pela equipe técnica da E/SUBE/CED/CT - Educação Física, da E/SUBE/ CED - Educopédia/ Rioeduca da SME-RJ, sob processo n 07/007.125/2015.

\section{FORMAÇÃO DE PROFESSORES E O USO DAS TECNOLOGIAS DIGITAIS}

Segundo Junior, Carvalho e Chahini (2016), existe um hiato quando se aborda sobre o uso das tecnologias na educação, especialmente na educação básica. Enquanto a presença de equipamentos eletrônicos, como notebook, datashow e tablet na educação infantil, ensino fundamental e ensino médio alcançaram um status social e se fortificaram entre um público atraído pelo uso dessas ferramentas, muitas instituições de ensino ainda não se instrumentalizaram de forma satisfatória para desfrutar dessas tecnologias no processo ensino-aprendizagem. Além de muitas escolas não estarem preparadas para receber esses materiais eletrônicos, muitos docentes não estão aptos a utilizá-los e desenvolverem um trabalho de forma educativa por meio das mídias. Muitas vezes, muitos utilizam as tecnologias de forma supérflua, ou seja, expõem o material no datashow, por exemplo, explica o conteúdo e não o explora de forma adequada. É preciso que o corpo docente compreenda e planeje de forma adequada o uso das tecnologias nas salas, criando algo inovador, para que a plataforma seja, efetivamente, utilizada no processo ensino-aprendizagem.

Junior, Carvalho e Chahini (2016) colocam que, na modernidade, há diversos aparelhos e equipamentos eletrônicos disponíveis no mercado. No entanto, para utilizá-los é preciso ter conhecimento, pois não basta ter um poder econômico para comprar algum aparelho, por exemplo, e não saber utilizar. Dessa forma, quanto mais moderno forem os equipamentos e aparelhos eletrônicos, mais conhecimentos e habilidades serão preciso para manuseá-los.

De acordo com Moraes et al. (2015), fica evidente que a falta de conhecimento e manuseio dos equipamentos eletrônicos por alguns professores possibilita a exploração de forma inadequada das tecnologias nas salas de aulas. Ratifica-se a necessidade da realização de cursos de aperfeiçoamento para os docentes, visando ao domínio das tecnologias, já que são importantes ferramentas na mediação do processo de ensino-aprendizagem.

Portanto, o processo de capacitação dos docentes com relação ao uso das tecnologias digitais nas salas de aulas, recai, muitas vezes, para cursos de formação continuada, visto que o currículo dos cursos de licenciaturas das universidades ainda não tem um destaque com relação à tecnologia, algo tão onipresente na sociedade (MAIA; BARRETO, 2012).

Moraes et al. (2015) reforça que, geralmente, o professor esbarra nos desafios enfrentados, como a infraestrutura e até mesmo a falta de prática em utilizar as tecnologias na aula, ao implementar as tecnologias digitais nas instituições de ensino, pois não adianta ter computadores e outros equipamentos digitais na escola, se o professor os utilizar para uma aula expositiva como no método tradicional, não correspondendo à necessidade presente. Portanto, "são necessárias mudanças que possam propiciar espaços e tempos pedagógicos adequados ao momento vivido em uma sociedade digital" (MORAES et al., 2015, p. 53). 
As novas tecnologias no ambiente escolar: resposta dos professores de Educação Física da Secretaria Municipal de Educação do Rio de Janeiro com relação a Educopédia

Dessa maneira, ofertar cursos ou capacitações aos professores é uma estratégia plausível, no entanto esses cursos não devem ser totalmente fechados com fins imediatos, nos quais os profissionais sejam apenas meros expectadores, mas que interajam e participem das discussões (MORAES et al. 2015).

Sabe-se que, na prática, a tarefa do docente consiste em ensinar, aprender, criar e estabelecer novas formas de aulas, ou seja, nova prática pedagógica. Portanto, de acordo com essa evolução das tecnologias no mundo moderno, há uma certa preocupação por parte de teóricos e pesquisadores que defendem o uso das tecnologias na educação, já que propor o uso das mídias nas salas de aulas requer mudanças pedagógicas inovadoras (MORAES et al. 2015).

\section{RESPOSTAS DOS PROFESSORES DE EDUCAÇÃO FÍSICA DA SME-RJ COM RELAÇÃO À PLATAFORMA EDUCOPÉDIA}

Questionamos os docentes se a preparação das aulas de educação física demandaria mais tempo em virtude da montagem dos equipamentos tecnológicos e acesso à plataforma (Gráfico 1). Tivemos, nessa questão, 126 respondentes, dentre os quais 53 não concordaram nem discordaram, 33 concordaram, 19 concordaram plenamente, 16 discordaram, 5 discordaram plenamente e 34 não responderam ou não quiseram opinar.

Pelo que é apresentado nas respostas dos professores com relação à montagem dos equipamentos (como instalar datashow, ligar o computador e caixa de som), apesar de demandar tempo, não é o suficiente para que invalide seu uso nas aulas. Nesse aspecto, os professores são bem positivos em suas respostas, desconsiderando uma interferência relevante a não utilização da Educopédia. No entanto, há escolas da rede em que esses equipamentos já estão instalados nas salas de aulas, o que agiliza o trabalho do docente, que precisa apenas ligar os cabos nos computadores e iniciar a aula.

Gráfico 1 - Demonstração do tempo gasto para montagem dos equipamentos tecnológicos na concepção dos professores entrevistados

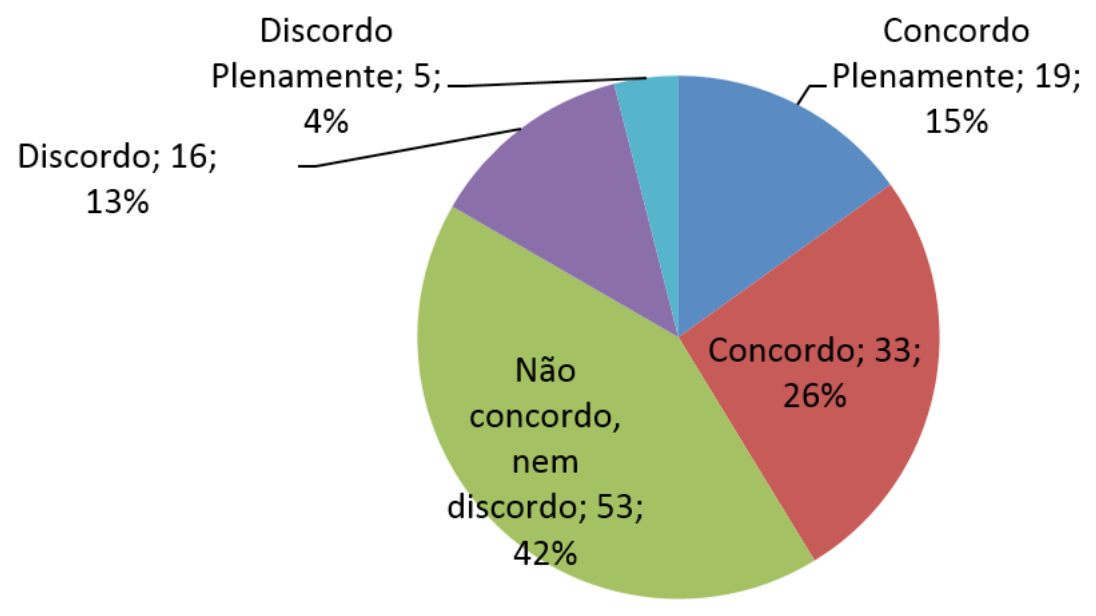

Fonte: elaborado pelos autores. 
Perguntamos aos professores se a navegação na plataforma era simples e se conseguiam passar rapidamente de uma tela a outra (Gráfico 2). Tivemos 125 professores que responderam a essa questão, sendo 54 que não concordaram nem discordaram da afirmação, 42 concordaram, 16 discordaram, 9 concordaram plenamente, 4 discordaram plenamente e 35 não responderam ou não quiseram opinar.

Nota-se que $59 \%$ dos professores criticam a navegação na plataforma, alegando que passar de uma tela para outra não é tão fácil, ou seja, não é tão prático. Acreditamos que é preciso melhorar a usabilidade da plataforma, já que mais da metade dos professores respondentes alegam não conseguir passar rapidamente de uma tela a outra, não explorando as aulas de forma eficaz, demandando tempo, já que o professor tem que ir clicando nas setas para passar para outros slides.

Além disso, ao final de cada aula, não há a possibilidade do professor voltar para o primeiro slide diretamente, caso queira mostrar algum vídeo ou imagem, por exemplo. Ressalta-se que essa situação acontece quando o professor está utilizando a Educopédia on-line. Vimos também que $41 \%$ acreditam que não há problemas com relação à essa situação e que esse modelo de navegação não interfere nas suas aulas.

Gráfico 2 - Considerações sobre a navegação na Plataforma Educopédia

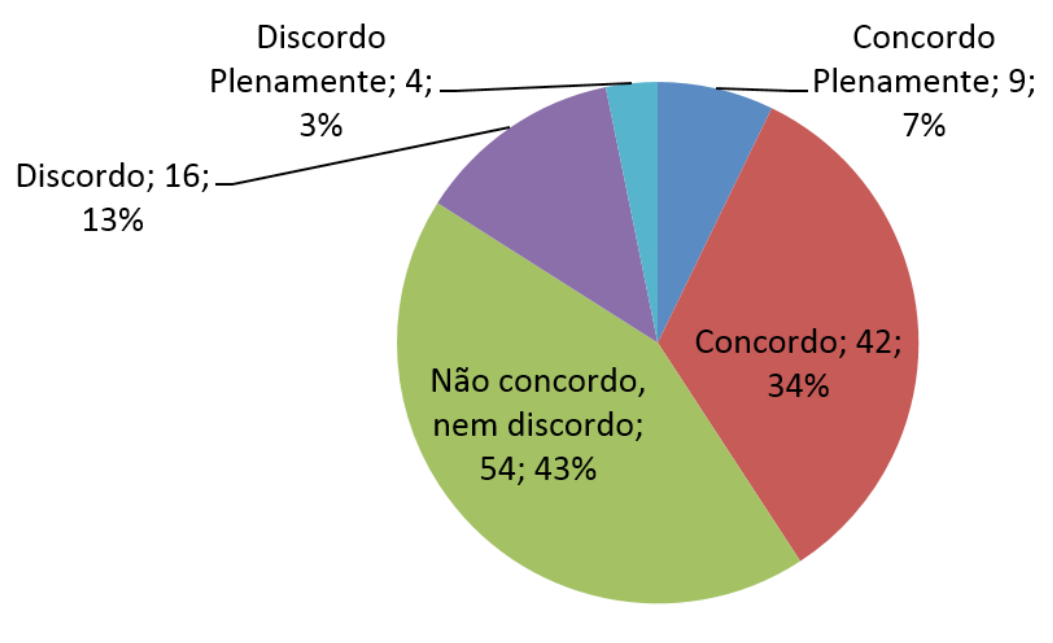

Fonte: elaborado pelos autores.

Quando perguntados se era possível trabalhar interdisciplinarmente por meio da Educopédia (Gráfico 3), notamos que 60 professores concordaram com a afirmação, 45 não concordaram nem discordaram, 13 concordaram plenamente, 5 discordaram, 1 discordou plenamente e 36 não responderam ou não quiseram opinar.

Constata-se que $59 \%$ dos professores aprovaram e concordaram que é possível trabalhar interdisciplinarmente por meio da plataforma, destacando a possibilidade de estabelecer um diálogo entre as disciplinas. Para Alves et al. (2004) por meio da prática interdisciplinar, é possível achar uma possível solução para a disciplinaridade, de modo que é apontado como uma interferência que precisa ser vencida. Assim,

A interdisciplinaridade faz-se mister a intercomunicação entre as disciplinas, de modo que resulte uma modificação entre elas, através de diálogo compreensível, uma vez que a simples troca de informações entre as organizações disciplinares não constitui um método disciplinar. (JAPIASSÚ, 1976 apud ALVES et al. 2004, p. 141).

Nota-se, portanto, que é um ponto bem positivo, pois, apesar de haver críticas referentes à plataforma, há essa possibilidade de trabalhar a educação física com as demais disciplinas de forma interdisciplinar. 
As novas tecnologias no ambiente escolar: resposta dos professores de Educação Física da Secretaria Municipal de Educação do Rio de Janeiro com relação a Educopédia

Gráfico 3 - Considerações sobre a possibilidade de se trabalhar interdisciplinarmente na Plataforma Educopédia

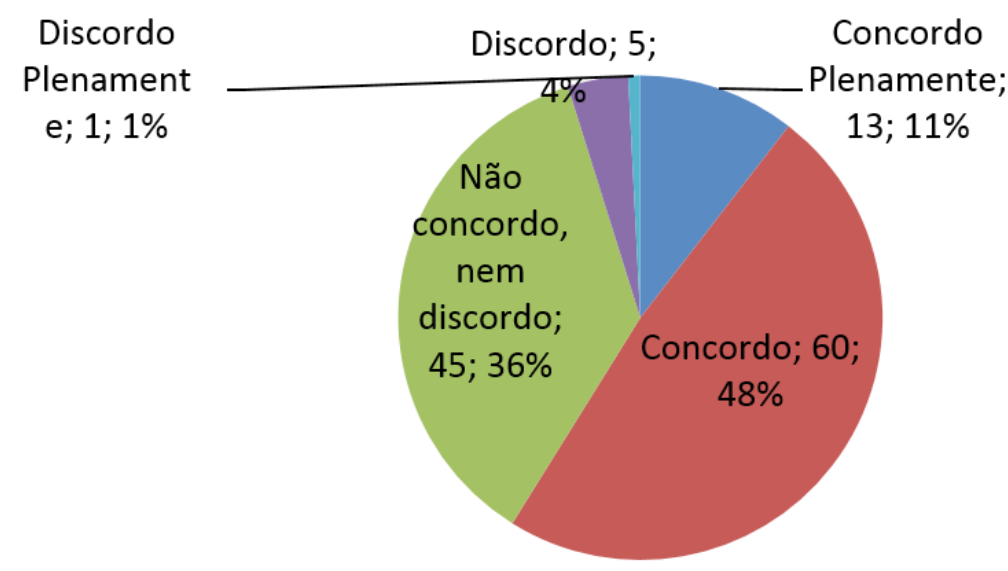

Fonte: elaborado pelos autores.

Perguntamos também se recomendariam a Educopédia para outros docentes de educação física (Gráfico 4). Tivemos 126 respondentes nessa questão: 58 concordaram, 40 não concordaram, nem discordaram, 18 concordaram plenamente, 7 discordaram, 3 discordaram plenamente e 34 não responderam ou não quiseram opinar.

As respostas dos professores foram positivas, pois verifica-se que, apesar das limitações da plataforma, os professores indicariam a Educopédia para outros docentes de educação física.

Gráfico 4 - Recomendação para utilização da Educopédia por professores de Educação Física

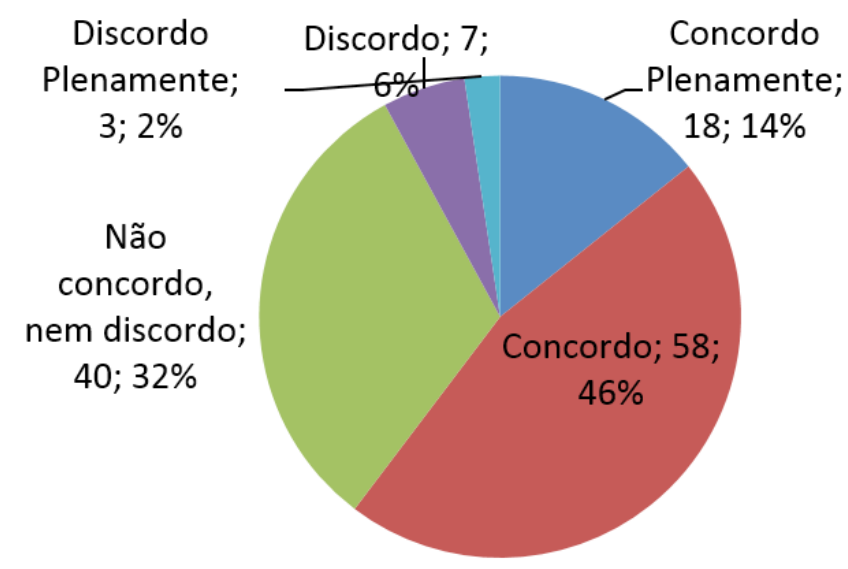

Fonte: elaborado pelo autor.

Assim, nota-se que muitos professores acreditam que as aulas da Educopédia não substituem outros meios, como os textos ou aulas estruturadas em PowerPoint.

Apesar das críticas em relação à Educopédia, os docentes acreditam que é possível trabalhar de forma interdisciplinar por meio dessa ferramenta e que os professores a recomendariam a outros docentes recém-chegados à rede, além de utilizá-la em outras redes de ensino. 


\section{CONSIDERAÇÕES FINAIS}

Diante do que foi apresentado, percebe-se que os professores de Educação Física da Rede Municipal de Educação do Rio de Janeiro que participaram deste estudo não são resistentes à utilização da Educopédia para aperfeiçoamento das aulas de Educação Física, mas acreditam que a plataforma necessita de alguns ajustes. A partir dos resultados adquiridos por meio da investigação, é notável que as tecnologias fazem parte do cotidiano desses professores.

É importante ressaltar que este estudo limitou-se a um número específico de docentes, pois apenas alguns responderam ao questionário, sendo necessário, assim, que estudos sejam desenvolvidos também em outras regiões. Isso fará com que tracemos, de fato, o real cenário dos ambientes escolares de nível fundamental com relação ao uso das novas tecnologias, visando à aproximação do currículo escolar à realidade dos alunos.

Assim, o estudo concluiu que, apesar de demandar tempo quanto à montagem dos equipamentos tecnológicos para acessar à Plataforma, tal fato não é o suficiente para invalidar seu uso nas aulas, pois a Educopédia apresenta conteúdos de qualidade, além de possibilitar o trabalho de forma interdisciplinar e ser indicado para outros profissionais.

\section{REFERÊNCIAS}

ALARCÃO, I. Escola reflexiva e a nova racionalidade. Porto Alegre: Artmed, 2001.

ALVES, R.F.; BRASILEIRO, M.C.E.; BRITO, S.M.O. Interdisciplinaridade: um conceito em construção. Episteme, Porto Alegre, n. 19, p. 139-148, 2004CASTELLS, M. A sociedade em rede. São Paulo: Paz e Terra, 1999.

GUERREIRO, J.R.G.; BATTINI, O. Novas Tecnologias na Educação Básica: desafios ou possibilidades? Disponível em: <http://www.uel.br/eventos/jornadadidatica/pages/arquivos>. Acesso em: 16 fev. 2019.

JAPIASSU, H. Interdisciplinaridade e patologia do saber. Rio de Janeiro: Imago, 1976.

JUNIOR, J.B.B.; CARVALHO, H.V.; CHAHINI, T.H.C. Educação básica e o uso das Tecnologias digitais: Percepções e perspectivas. Educere et Educere. v. 11, n. 22, p. 1-11, 2016.

MAIA, D.L.; BARRETO, M.C. Tecnologias digitais na educação: uma análise das políticas públicas brasileiras. Revista educação, formação \& tecnologias, v. 5, n. 1, p. 47 61, 2012.

MORAES, D.A.F.; OLIVEIRA, D.E.M.B.; BROIETTI, F.C.D.; STANZANI, E.L. O uso das tecnologias digitais por professores da escola básica: realidades do contexto educativo. B. Tec. Senac, Rio de Janeiro, v. 41, n. 2, p. 48-63, 2015. 